\title{
SOCIEDADE BRASILEIRA DE UVEÍTES
}

\section{Toxoplasmose - Levantamento bibliográfico de 1997 a 2000}

\author{
Toxoplasmosis -Literature review(1997 to 2000)
}

\author{
Cláudio Silveira ${ }^{1}$
}

\section{INTRODUÇ̃̃O}

As pesquisas na área da toxoplasmose são de grande importância, por esta doença se constituir numa das zoonoses de maior difusão no mundo em que vivemos.

No Brasil no mínimo 6 mil bebês nascem por ano com infecção congênita, que é evitável com orientação dietética e acompanhamento sorológico. Nos EUA as infecções durante a gravidez ocorrem em 2 casos por mil nascimentos, com até $50 \%$ de infecção transplacentária.

A toxoplasmose ocular é a causa mais comum de inflamação retiniana em pacientes não imunocomprometidos e uma das mais importantes infecções oculares secundárias em pacientes com AIDS.

A transmissão transplacentária ou congênita foi a primeira a ser conhecida como causadora das lesões em humanos. As maneiras mais comuns de contágio são o consumo de alimentos contaminados e o contato com fezes de gato e terra. A importância da toxoplasmose congênita como causa da toxoplasmose ocular passa a ser reconhecida a partir dos trabalhos de Wilder $1952^{(1)}$ e Perkins $1973^{(2)}$. Setenta por cento das infecções congênitas terão cicatrizes retinocoroideanas.

A doença adquirida, que se pensava ser pouco freqüente, era relatada em raros trabalhos publicados. Em 1978 Masur publica um caso de retinocoroidite toxoplásmica associada à toxoplasmose adquirida, assim como Akstein et al. $1982^{(3)} \mathrm{e}$ Green, $1994^{(4)}$.

Silveira et al. $1987^{(5)}$, Glasner et al. $1992^{(6)}$ e Belfort Jr et al. $1999^{(7)}$, publicam trabalhos com mais de 150 famílias com vários irmãos não gêmeos com lesão ocular, estudos de base populacional com $20 \%$ dos casos apresentando mais de um irmão não gêmeo com lesão e também casos de mãe com sorologia negativa e filhos com lesões oculares. Estas foram as primeiras publicações onde um número significativo de casos de doença adquirida foram apresentados.

Tradicionalmente a toxoplasmose adquirida é considerada uma doença benigna e auto-limitada em indivíduos saudáveis

${ }^{1}$ Doutor em medicina pela Universidade Federal de São Paulo - UNIFESP e imunocompetentes, sendo o tratamento considerado desnecessário, uma vez que muitos pacientes não desenvolvem complicações mais severas. Recentes trabalhos mostraram que indivíduos com toxoplasmose adquirida apresentam o risco de desenvolver tardiamente lesões oculares que comprometem de forma irreversível a visão. Portanto, é adequado reconsiderar o uso do antiparasitário no momento da aquisição da infecção.

Recentemente, novas características clínicas foram associadas à toxoplasmose ocular; reações inflamatórias intra-oculares incomuns podem ser a única manifestação de uma toxoplasmose ocular adquirida. Hoje em dia já não podemos afirmar que a toxoplasmose ocular causa sempre uma retinocoroidite necrótica focal, porque na infecção adquirida outras partes do olho podem ser afetadas, sem desenvolvimento de retinite. Alguns pacientes desenvolvem somente vasculite, outros somente vitreíte ou somente iridociclite. São chamadas de formas atípicas.

$\mathrm{O}$ aperfeiçoamento dos exames laboratoriais facilitaram o diagnóstico da doença, como a Avidez de IgG, o PCR e o Elisa. O PCR no humor aquoso, vítreo e sangue periférico passaram a ser importantes nos últimos anos.

Em relação ao tratamento existem novas drogas promissoras, como o Rifabutin, a Claritromicina, o Atovaquone e a Azitromicina, que apresentam menor toxicidade do que a Sulfadiazina e a Pirimetamina, que permanecem como as drogas de primeira escolha.

\section{1 - Epidemiologia}

Altintas et al. $1997^{(8)}$, testaram 9410 pacientes de diferentes faixas etárias, atendidos no Departamento de Parasitologia da Ege University, Bornova - Izmir, Turquia, entre 1991 e 1995 . O teste utilizado foi IFA e Elisa. O teste de IgG foi positivo em 4651 pacientes (49,4\%) 2287 (21,4\%) eram mulheres grávidas e entre elas a positividade do IgG foi de $55 \%$. Não foi encontrada relação significativa entre a soropositividade e abortos, prematuros e alterações fetais ao nascimento.

Joshi et al. $1998^{(9)}$, testaram 135 voluntários sadios, sendo 65 adultos e 50 crianças. O teste utilizado foi Elisa para anticorpos antitoxoplasma da classe IgG e IgM. A soropositividade para IgG ou IgG e IgM foi de $17,2 \%$ e $4 \%$ apresen- 
taram IgM positivo ou IgG $>210 \mathrm{Eu} / \mathrm{ml}$. Não foram encontradas diferenças significativas entre nível de anticorpos em relação a sexo/ status socioeconômico/ lugar onde mora/ rural ou urbano/ e hábitos alimentares (vegetarianos ou não vegetarianos).

Jain et al. $1998^{(10)}$, estudaram 200 casos de uveítes e 100 controles, usando teste de IF p/ IgG e IgM e ELISA. Os casos foram divididos em 4 grupos: com uveíte anterior, posterior, pan-uveíte e outras manifestações de uveítes. A soropositividade foi de $32 \%$ dos casos e $4 \%$ nos controles. Os casos com uveíte posterior foram $41,7 \%$ soropositivos. A soropositividade foi maior entre os 16 e 25 anos de idade, sem predominância de sexo.

Abreu et al. $1998^{(11)}$, realizaram um estudo populacional para conhecer a prevalência da toxoplasmose ocular em Venda Nova do Imigrante, ES, e compará-la com a prevalência de lesões em outras regiões do Brasil. De 1074 pessoas examinadas, $11,27 \%$ foram diagnosticadas como portadoras da toxoplasmose ocular, baseado em achados fundoscópicos. Esta prevalência foi superior à existente nos Estados Unidos $(0,6 \%)$ e em São Paulo (9\%), mas inferior à de Erechim, RS $(17,7 \%)$.

Garcia et al. 1999 ${ }^{(12)}$, testaram 345 moradores na área rural de Juaguapita, no estado do Paraná. Os títulos das amostras humanas foram comparados aos títulos encontrados em 1420 amostras de animais que habitam a mesma região e tem contato com seus moradores. $\mathrm{O}$ mais alto título encontrado foi $65,536(1 \%)$ e o título mais freqüente foi $256(29 \%)$ e 1024 (19\%). As comparações entre humanos e animais revelaram uma significativa correlação entre humanos e felinos ( $\mathrm{r}=0,78$; $\mathrm{p}=0,01)$ e humanos e caninos $(\mathrm{r}=0,64 ; \mathrm{p}=0,05)$ em termos da distribuição de títulos. Os participantes do estudo foram testados com a Tela de Amsler. Setenta e cinco das 345 pessoas (22\%) tinham queixa de diminuição da visão. Destes 75,58 pessoas $(77 \%)$ eram soropositivas para toxoplasmose. Quarenta e uma destas 58 pessoas passaram por um exame oftalmológico e 9 delas apresentaram lesões sugestivas de toxoplasmose. Elas tinham entre 34 e 78 anos de idade. Nenhuma delas apresentava sinais de inflamação ocular. Seis destes 9 pacientes (67\%) tinham lesão unilateral; 4 destes 6 apresentavam títulos de 256. A avaliação epidemiológica mostrou que a possibilidade de apresentar problemas oculares foi 2,06 vezes maior para pacientes reagentes do que para os não reagentes. Nenhuma diferença significativa foi observada em termos de sexo, contato com felinos e outros animais, consumo de carne crua ou mal passada e leite cru e abate de animais para consumo próprio. Segundo os autores, os resultados sugerem que a toxoplasmose é comum na região, com uma incidência significativa de lesões oculares causadas pelo $T$. gondii.

Gilbert et al. $1999^{(13)}$, estudaram 87 casos sintomáticos que receberam diagnóstico de infecção por toxoplasma. Somente 2 dos 87 casos apresentaram sintomas antes dos 10 anos de idade. Os autores concluíram que a apresentação tardia da doença sugere que a etiologia da doença se divide entre forma adquirida após o nascimento e forma congênita, e que os cuidados de prevenção primária devem ser aplicados aos dois grupos.

Oréfice et al. $1999^{(14)}$, realizaram um estudo de prevalência da toxoplasmose ocular no município de Campos dos Goitacazes, RJ, onde foram avaliados 1050 indivíduos com relação à sorologia, presença de lesões oculares e fatores de risco referentes à infecção pelo Toxoplasma gondii. Concluíram que a prevalência elevada de infecção toxoplásmica foi maior nas populações de baixo poder aquisitivo, em comparação com a população de médio/alto poder aquisitivo. A prevalência de lesões oculares parece não diferir entre os dois grupos estudados, sendo de $10 \%$ em ambas as populações.

\section{2 - Toxoplasmose congênita}

Kamiyama et al. $1997^{(15)}$, examinaram uma menina que apresentava opacidades vítreas e uma retinite focal ativa no olho direito. No olho esquerdo apresentava uma cicatriz de retinocoroidite focal. Possuía teste de ELISA positivo para IgG anti-toxoplasma e negativo para anticorpos IgM. Acreditam que essa forma de apresentação, com retinite focal em um olho e cicatriz de retinocoroidite focal no outro olho, seja rara em toxoplasmose congênita.

Mets et al. $1997^{(16)}$, realizaram um estudo prospectivo longitudinal com 76 recém-nascidos com toxoplasmose congênita, que foram tratados com pirimetamina e sulfadiazina por aproximadamente 1 ano e 18 indivíduos não tratados durante o primeiro ano de vida. O resultado mostrou que a cicatriz coriorretiniana foi o achado mais comum e foram mais comuns na periferia, em $58 \%$ do grupo tratado e $82 \%$ do grupo não tratado. A cicatriz macular estava presente em $54 \%$ dos pacientes tratados, $41 \%$ eram bilaterais, e as cicatrizes maculares estavam presentes em $76 \%$ dos pacientes não tratados e $23 \%$ eram bilaterais. A acuidade visual, na presença de lesões maculares, variava entre $20 / 20$ a 20/400. Concluíram que o tratamento de crianças com toxoplasmose congênita no primeiro ano de vida é benéfico e, em alguns casos, é possível conseguir boa acuidade visual, mesmo na presença de lesões maculares grandes.

Melamed et al. $1998^{(17)}$, realizaram um estudo para avaliar a freqüência e o tipo de alterações tomográficas cerebrais em pacientes com toxoplasmose congênita apresentando retinocoroidite. Foram avaliados 15 pacientes que preencheram os critérios para seleção da amostra. $\mathrm{O}$ achado radiológico mais freqüente foram as calcificações encefálicas, presentes em $73,3 \%$ dos pacientes. A segunda alteração mais comum foi a dilatação ventricular, presente em $20 \%$ dos pacientes. Também foram observados: cisto porencefálico, hidroanencefalia, hidrocefalia, dilatação da cissura de Sylvius, hipodensidade de lobos frontais e cisto de aracnóide, presentes em 6,7\% dos pacientes, cada alteração. Somente $20 \%$ dos pacientes não tinham alterações cerebrais presentes na tomografia computadorizada.

Ianaguihara et al. $1998^{(18)}$, descrevem um caso de transmissão congênita de toxoplasmose, com acometimento ocular 
bilateral, em gêmeas univitelinas. O diagnóstico só foi possível quando uma das meninas apresentou baixa da acuidade visual, com reativação de toxoplasmose ocular, aos 15 anos de idade. Ao exame fundoscópico, foi notado placas de retinocoroidite bilaterais em ambas as gêmeas e na mãe das crianças, cuja forma de transmissão ocorreu durante uma contaminação da mãe adquirida durante a gestação das gêmeas.

O'Neil 1998 (19), estudou as conseqüências oculares de infecções por toxoplasma durante a gestação. 21 são casos de toxoplasmose, com diagnóstico clínico e confirmação sorológica foram estudados por 24 anos, examinados e acompanhados entre 1967 e 1991. A maior razão para o primeiro exame foi a presença de desvio ocular. Destas 21 crianças, 12 (57\%) tinham entre 3 meses e 4 anos de idade e diagnóstico inicial de estrabismo e as outras nove com queixas menores ou cujo diagnóstico fazia parte da rotina dos exames. Este estudo confirmou que os danos fetais podem resultar de infecções intra-uterinas e seus efeitos podem continuar ocorrendo até 20 anos após a infecção.

Malm et al. $1999^{(20)}$, realizaram estudo prospectivo para definir a incidência de toxoplasmose congênita naquele país. Foram coletadas amostras de sangue em papel filtro de 40978 recém-nascidos, que foram analisadas para IgM e IgG antitoxoplasma. Um relato preliminar mostrou 3 crianças com toxoplasmose congênita, definida pela detecção de anticorpos IgM. Duas crianças eram assintomáticas ao nascer. Elas tiveram desenvolvimento normal até os 12 e 15 meses de vida, respectivamente. A terceira criança teve a toxoplasmose congênita confirmada e foi instituído o tratamento. A criança apresentava microftalmia e retinocoroidite periférica num dos olhos. Apesar dos medicamentos desenvolveu hidrocefalia, necessitando de neurocirurgia aos 3 meses de idade. Seu desenvolvimento até os 14 meses foi normal. A incidência de toxoplasmose congênita na Suécia, detectada pelo IgM específico em sangue no papel-filtro é menor que 1:10000.

\section{3 - Toxoplasmose adquirida}

Burnett et al. $1998^{(21)}$, observaram as manifestações oculares da toxoplasmose adquirida em um "outbreak" da doença. A toxoplasmose adquirida após o nascimento foi determinada em 15 pacientes que se infectaram com a água do reservatório da cidade. Vinte dos 112 pacientes desenvolveram lesão ocular. Dos 20 pacientes, 19 apresentavam lesão unilateral e um, lesão bilateral. Quinze das 21 lesões estavam ativas e melhoraram após tratamento, com exceção de 3 casos de lesão macular e 3 casos com vitreítes persistentes.

Pereira et al. $1999^{(22)}$, através de um modelo experimental para toxoplasmose adquirida e congênita, induziram uveíte auto-imune (EAU) em Calomys callosus. Toxoplasma gondii, cepa ME-49, foi usado para infectar machos e fêmeas, grávidas ou não, enquanto o antígeno-S era usado para induzir EAU. As lesões oculares obtidas pelo T. gondii se caracterizavam pela presença de cistos, taquizoítos livres e células inflamatórias na retina. Na forma congênita, $40 \%$ dos fetos apresentaram lesões oculares, presença de cistos na retina e vítreo. Na forma adquirida, $75 \%$ das fêmeas e $50 \%$ dos machos apresentaram cistos oculares unilaterais, 21 a 47 dias após a infecção. Também foi demonstrado que o antígeno-S não foi causador de uveítes em Calomys callosus. Concluíram que o C. callosus pode constituir-se num modelo animal promissor para estudos sobre toxoplasmose adquirida e congênita, especialmente quando nenhum processo auto-imune estiver envolvido na origem da infecção ocular.

Stanford, Gilbert $1999^{(23)}$, analisaram estudos de base populacional em busca de uma estimativa do número de casos que seriam causados por doença congênita ou doença adquirida após o nascimento. Ao analisar a literatura, referências 1 , 2,26 e 29 , chegaram ao número de $0,3 \%$ para a menor estimativa e $80 \%$ para a maior estimativa. A conclusão foi de que, com os dados disponíveis atualmente, a estimativa que se pode fazer é que, pelo menos $2 / 3$ dos pacientes que apresentam toxoplasmose ocular adquiriram a infecção após o nascimento em vez da forma congênita. Sugerem que os controles de prevenção devem ser aplicados não só para gestantes mas também para crianças e adultos com risco de desenvolverem lesões oculares.

Holland et al. 1999(24), descreveram a ocorrência de reações inflamatórias sem retinocoroidite como manifestações da toxoplasmose sistêmica adquirida. Foram analisados os dados de 10 pacientes com uveítes e evidências de infecção recente por Toxoplasma gondii. A vasculite retiniana, associada com reações inflamatórias, pode ser a única manifestação oftalmológica nos estágios iniciais da toxoplasmose adquirida recente. O posterior aparecimento de retinite e cicatrizes, consistentes com a retinocoroidite toxoplásmica nos mesmos olhos, sugerem que a inflamação inicial pode ser causada pela presença de parasitas no tecido retiniano.

Yamamoto et al. $2000^{(25)}$, analisaram a resposta imune entre pacientes com toxoplasmose adquirida e toxoplasmose congênita. Foram coletadas amostras de sangue de 136 pacientes entre 18 e 64 anos de idade. Vinte e seis pacientes apresentavam títulos de anticorpos para toxoplasmose da classe IgG e $\operatorname{IgM},>1: 4$, considerados soronegativos. Todos os outros tinham títulos positivos para toxoplasma, de $\operatorname{IgM}$ ou $\operatorname{IgG}<1: 64$. Os resultados mostraram que os pacientes com toxoplasmose ocular adquirida apresentaram respostas maiores para células $\mathrm{T}$ quando estimuladas com antígenos anti-toxoplasma do que os pacientes soropositivos assintomáticos. As pessoas com toxoplasmose ocular adquirida secretaram também maiores quantidades de IL1, TNF $\alpha$ e IL10 do que o grupo assintomático. Os dados mostraram que a resistência à infecção pode estar ligada à habilidade de secretar altos índices de IL12 (interleucina 12). Foi muito significativo o resultado dos pacientes com toxoplasmose congênita, que apresentaram resposta proliferativa de linfócitos menor. Eles secretavam menos interleucina 2 e IFN STAg do que os pacientes com diagnóstico de toxoplasmose ocular adquirida. A diminuição da resposta ao toxoplasma por antígenos $\mathrm{T}$ dos pacientes com 
toxoplasmose congênita sugerem que as células T específicas para Toxoplasma gondii podem ter sido anergizadas ou destruídas através da exposição aos antígenos do toxoplasma no período pré-natal. Os achados foram importantes porque mostram testes de laboratório que podem diferenciar a toxoplasmose adquirida da congênita e sugerem que o mecanismo que envolve o desenvolvimento da lesão ocular pode ser diferente nas duas formas da doença, apesar da aparência semelhante no aspecto patológico.

\section{4 - Toxoplasmose e AIDS}

Joag et al. 1997(26), encontraram, após inoculação do vírus SHIV em macacos, presença de patógenos oportunistas como: pneumocistis, citomegalovírus, criptosporidium, toxoplasma e cândida.

Arevalo et al. 1997(27), encontraram predominância de toxoplasma em 120 pacientes HIV positivos com lesões retinianas em comparação com Mycobacterium avium. Observaram também que as lesões de retinocoroidite apresentavam cicatrizes com menos pigmento do que as encontradas em pacientes imunocompetentes.

Girard et al. 1997 ${ }^{(28)}$, analisaram 33 crianças HIV positivo e encontraram a toxoplasmose ocular como a manifestação mais comum.

Lanjewar et al. $1998^{(29)}$, diagnosticaram encefalite aguda por toxoplasma em $10(20,4 \%)$ dos 49 pacientes autopsiados, concluindo que o grande número de casos de toxoplasmose no SNC em pacientes com AIDS mostra a necessidade da doença ser incluída nos diagnósticos diferenciais.

Chakraborty $1999^{(30)}$, encontrou CMV como a manifestação ocular mais freqüente em pacientes HIV positivo, seguida de tuberculose, sífilis e toxoplasmose.

\section{5 - Exames sorológicos}

McHugh et al. $1997^{(31)}$, testaram soros de pacientes com doença ativa e cicatrizada pela análise Western blot, para tentar identificar os 2 grupos a partir de testes sorológicos. A conclusão foi de que os Cysts Derived Antigens não são bons marcadores da reativação da toxoplasmose.

Whittle et al. $1998^{(32)}$, estudaram a possibilidade de que os danos retinianos na toxoplasmose possam ser causados por mecanismos auto-imunes. Trinta e seis pacientes foram estudados, sendo 18 com a primeira recorrência e 18 com múltiplas recorrências. Concluíram que a extensão da reatividade antiretina na retinocoroidite toxoplásmica não é causada por anticorpos anti-antígeno S. Esta marcada alta prevalência de anticorpos anti-fotorreceptor na retinocoroidite toxoplásmica nos controles sugerem que estes anticorpos podem ser copatogênicos em retinocoroidite toxoplásmica.

Gómez Marin et al. 1997(33), estudaram a ação do T1 (gama interferon, interleucina12 e interleucina 2) que corresponde à resposta celular. A conclusão foi de que a toxoplasmose ocular em pacientes imunocompetentes pode ser atribuída a resposta celular $\mathrm{T} 1$.
Lappin et al. $1997^{(34)}$, estudaram o papel da interleucina 6 (IL-6) em uveítes em felinos. Soro e aquoso foram coletados de gatos clinicamente normais e dos que foram inoculados com a cepa ME49 de $T$. gondii. O resultado mostrou que IL-6 é produzida dentro do olho em gatos com uveítes e podem ser um mediador de uveítes em gatos.

Danise et al. $1997^{(35)}$, utilizaram a técnica de PCR para detecção de CMV, VZV, HSV e T. gondii no humor aquoso de pacientes HIV positivo. O resultado mostra CMV positivo em 5 casos, toxoplasmose em 4 casos e VZV em 2 casos. A técnica de PCR mostrou que é útil para determinar a etiologia das uveítes em pacientes HIV positivos.

Bornand, Gottrau $1997^{(36)}$, analisaram soro e humor aquoso de 90 pacientes, medindo o Coeficiente de Witmer-Desmonts, para avaliar a produção local de anticorpos e confirmar o diagnóstico clínico de toxoplasmose ocular. $\mathrm{O}$ resultado foi positivo em $41,1 \%$ dos casos, incerto em $13,3 \%$ e negativo em $45,6 \%$ dos casos.

Quentin, Reiber $1997^{(37)}$, analisaram 46 olhos com uveítes severas com a técnica de ELISA no soro e humor aquoso. Em 20 casos foi detectado síntese de anticorpos antitoxoplasma no humor aquoso. A análise do humor aquoso se mostrou mais eficiente do que a análise de anticorpos no soro isolado para diagnóstico de toxoplasmose ocular e podem aumentar o número de diagnósticos nos casos de uveítes.

Bernasconi et al. 1997(38), utilizaram angiografias por ICG em retinocoroidite toxoplásmica. Concluíram que, através da indocianina verde, é possível mostrar lesões inaparentes no exame clínico e na angiofluoresceinografia, e que podem ser localizadas pela ICG. Este exame pode fornecer novas informações sobre a fisiopatologia da doença.

Garweg et al. 1998 ${ }^{(39)}$, analisaram o humor aquoso e soro de 27 pacientes. Foram encaminhados para 2 laboratórios de referência para realização de $\operatorname{IgG}$, IgM e IgA e calcular o Coeficiente de Goldmann e Witmer. A avidez também foi testada, bem como a detecção de DNA do toxoplasma por PCR. Concluíram que nenhum dos métodos foi sensível o suficiente para estabelecer o diagnóstico, mas a combinação dos 4 métodos, entretanto, atinge uma sensibilidade alta o suficiente para justificar a análise do humor aquoso rotineiramente.

Ongkosuwito et al. $1998^{(40)}$, investigaram o papel do Thelper (citocinas) nas uveítes causadas por doenças infecciosas. Várias citocinas imunorreguladoras (IL-6, IL-10 e IFNgamma) foram detectadas em fluidos oculares de pacientes com uveítes. Um papel específico para T-helper tipol ou Thelper tipo 2 na patogênese de uveítes não pode ser provado.

Burney et al. 1998(41), analisaram o humor aquoso e soros de 5 gatos que foram inoculados oralmente com $T$. gondii. Três dos cinco gatos desenvolveram retinocoroidite. Todos os gatos desenvolveram anticorpos para toxoplasmose e o PCR foi positivo nos 2 olhos de todos os gatos.

Klaren et al. 1998 ${ }^{(42)}$, investigaram a especificidade da resposta de anticorpos antitoxoplasmose em amostras de humor aquoso e vítreo. As amostras de fluidos intra-oculares foram 
pareadas e comparadas com amostras de soro. A distinção entre doença recentemente adquirida e doença crônica foi feita através da presença de anticorpos antitoxoplasma da classe IgM. A especificidade dos anticorpos do tipo IgG foi analisada por imunoblot. As amostras foram coletadas de pacientes que apresentavam dúvidas quanto ao diagnóstico. Foram realizados os testes rotineiros para produção de anticorpos intraoculares, analisando T. gondii, herpes simples, varicela zoster e citomegalovírus. Também foi feita a reação de PCR para localizar a presença de DNA desses parasitas. Os casos em que foram utilizados vítreo eram os casos que tinham tido indicação de vitrectomia, com opacidades importantes. As amostras de humor aquoso foram analisadas com o objetivo de conseguir o melhor diagnóstico. Dois dos 13 pacientes testados apresentavam IgM positivo e foram considerados como tendo toxoplasmose ocular adquirida. A especificidade dos anticorpos nos fluidos oculares nestes dois pacientes foi similar, enquanto que nos pacientes com doença crônica foram observadas marcadas diferenças. Os resultados mostraram que a resposta intra-ocular de anticorpos anti-toxoplasma nos pacientes com toxoplasmose ocular recorrente é diferente daqueles pacientes com doença aguda. Uma das possibilidades para essa diferente resposta é que na forma adquirida da doença, a resposta imune humoral sistêmica estaria principalmente dirigida aos antígenos de taquizoítos, quando comparada a resposta sistêmica de pacientes crônicos, onde nós teríamos a resposta dividida entre taquizoítos e bradizoítos. Esta foi considerada pelos autores como sendo uma hipótese possível, mas como o número de casos foi pequeno, serão necessários estudos para que se tenha uma prova definitiva dessa hipótese.

Ronday et al. 1999(43), estudaram soro e humor aquoso pareados de 155 pacientes que foram testados para IgG, IgA e IgM. A presença de DNA de Toxoplasma gondii foi determinada por PCR. Em 88 dos 155 pacientes foi diagnosticado o toxoplasma. Entre estes 88 pacientes, $65 \%$ apresentaram produção de IgG intraocular, 52\% produção de $\operatorname{IgA}$ intraocular, $37,5 \%$ apresentaram produção de $\operatorname{IgG}$ e $\operatorname{IgA}, 27 \%$ tiveram só produção de $\operatorname{IgG}$ e $15 \%$ só produção de $\operatorname{IgA}$. Dos 13 pacientes testados só um apresentou produção de IgM. A conclusão foi de que a imunoglobulina $\mathrm{G}$ está presente com maior freqüência na resposta humoral contra o toxoplasma, seguido por IgA. A determinação de IgA mostrou ser útil como teste adicional para diagnóstico de toxoplasmose ocular.

Paul 1999(44), estudou o Teste de Avidez de IgG como marcador de doença aguda em 23 pacientes com clínica de doença adquirida recentemente. $\mathrm{O}$ resultado mostrou que a avidez foi menor que $30 \%$ em todos os casos. Em 10 crianças suspeitas de terem reativação de doença congênita, todas apresentaram avidez maior que $40 \%$. A conclusão foi de que o Teste de Avidez de IgG é um bom marcador de doença aguda em gestantes, podendo ser utilizado para diferenciar as reativações de infecção congênita da toxoplasmose ocular recentemente adquirida.
Chapman et al. 1999(45), estudaram a relação entre toxoplasmose ocular e o nível de anticorpos para toxoplasmose. Concluíram que Dye Test com títulos $\geq 65 \mathrm{UI} / \mathrm{ml}$ são compatíveis com toxoplasmose ocular e que títulos menores sugerem outras causas para lesões oculares.

Montoya et al. 1999(46), analisaram amostras de vítreo em 15 pacientes pelo método de PCR para confirmar o diagnóstico de toxoplasmose ocular. Entre março de 1994 e abril de 1996, foram coletadas amostras de vítreo de pacientes que apresentavam lesões atípicas de retinocoroidite toxoplásmica. Foram consideradas lesões atípicas quando os pacientes apresentavam lesões multifocais, retinites semelhantes a vírus como as causadas por necrose aguda, vitreíte, retinite periférica, vasculite retiniana, hemorragia intra-retiniana significativa e ausência de uma lesão de cório-retina visível no oftalmoscópio. Em sete dos quinze pacientes as amostras de vítreo foram positivas para a presença de DNA de $T$. gondii. Cinco dos 7 pacientes apresentavam sorologia compatível com doença adquirida há vários anos e em 2 pacientes a doença era consistente, com retinocoroidite concomitante com toxoplasmose aguda. Os autores concluíram que a utilização de PCR para identificação de toxoplasma no vítreo, em pacientes com retinocoroidite presumidamente toxoplásmica, nos quais a apresentação seja atípica ou a resposta com o tratamento específico antitoxoplasma não tenha sido adequada, pode auxiliar na confirmação do diagnóstico.

Bou et al. 1999(47), estudaram 56 pacientes com amostras de sangue e humor aquoso em pacientes imunocompetentes. $\mathrm{O}$ resultado que os autores encontraram mostrou que, em todos os casos em que o PCR para toxoplasmose foi positivo no humor aquoso, também foi positivo no sangue periférico. A conclusão dos autores foi de que não é necessária a punção da câmara anterior porque o resultado pode ser conseguido com o exame do sangue periférico.

Roberts et al. $2000^{(48)}$, estudaram o papel do óxido nítrico na patogênese da toxoplasmose ocular crônica. Os resultados demonstraram o papel de proteção do óxido nítrico no controle da toxoplasmose ocular crônica.

Nagineni et al. $2000^{(49)}$, estudaram culturas de células do epitélio pigmentar de retina humana para investigar a resposta celular primária das células retinianas e replicação do $\mathrm{T}$. gondii. Concluiram que a infecção pelo $T$. gondii induz a secreção de interleucina 1 (IL-1), IL-6 e fatores de estimulação de macrófagos e granulócitos pelas células do epitélio pigmentar da retina.

Gareweg et al. 2000 ${ }^{(50)}$, analisaram humor aquoso e sangue periférico de 45 pacientes com clínica de toxoplasmose ocular. Os testes realizados foram para IgG total, IgG específico, IgM, IgA PCR e Avidez. Alíquotas de humor aquoso de 150 a $250 \mathrm{ml}$ foram coletadas por paracentese. O sedimento obtido após centrifugação das amostras foi dissolvido em $50 \mathrm{ml}$ de solução de proteinase $\mathrm{K}$, que foi utilizada para amplificação de DNA de T. gondii. O sobrenadante foi utilizado para análise de imunoglobulinas. Entre os 49 episódios de toxoplasmose ocular, o 
exame foi positivo em amostras de humor aquoso e soro pareadas. Quando foram utilizados os resultados de 1 laboratório, o resultado foi positivo em 21 episódios (42,9\%). Quando foram utilizados 2 laboratórios, o resultado foi positivo em 15 episódios $(30,6 \%)$. O IgM foi positivo em 5 casos no soro e em 2 deles também foram positivos no humor aquoso. A identificação do DNA do parasita por PCR reforçou o diagnóstico em 6 de 39 pacientes (16\%). O teste de avidez foi positivo em 8 dos 43 casos testados (19\%). O IgA específico para T. gondii foi encontrado no humor aquoso de 11 dos 43 pacientes (26\%). A medida do IgA específico para $T$. gondii contribui substancialmente para o diagnóstico. Segundo os autores, a análise pareada de humor aquoso e soro permitem a confirmação do diagnóstico em 50 a $80 \%$ dos casos.

Jones et al. 2000(51), compararam a sensibilidade três gens de $T$. gondii humor aquoso, através de PCR. Foram comparados gen $\mathrm{B} 1$, gen $\mathrm{P} 30$ e gen ribossomal. A reação de amplificação do DNA de $T$. gondii no humor aquoso do gen B1 foi capaz de detectar, na primeira passagem, 1 pg de $T$. gondii. Após uma segunda passagem foi possível a detecção de $50 \mathrm{fg}$ de DNA de $T$. gondii (equivalente a 1 taquizoíto isolado). A amplificação do DNA de $T$. gondii do gen P30 no humor aquoso mostrou, na primeira passagem, a detecção de $1 \mathrm{ng}$ de DNA de $T$. gondii. Na segunda passagem a amplificação foi capaz de detectar 1 pg de DNA de T. gondii. A amplificação do DNA de $T$. gondii do gen ribossomal foi capaz de detectar 1 pg de DNA de $T$. gondii.

No humor aquoso somente a amplificação do gen B1 atingiu um nível de sensibilidade de $50 \mathrm{fg}$ de DNA de $T$. gondii. A amplificação do gen P30, também no humor aquoso, detectou um nível de 1 pg de DNA de $T$. gondii. O gen ribossomal foi o menos sensível dos três. A amplificação do gen B1, além da vantagem de ser mais sensível, mostrou-se também mais específico do que os gens P30 e ribossomal. Os primers do gen B1 não amplificaram DNA de bactérias ou fungos e a sensibilidade se mostrou inalterada na presença de DNA humano e também na presença de proteínas encontradas no humor aquoso inflamado. Os autores concluíram que o protocolo que utiliza PCR para detectar o gen B1 não é somente altamente específico na amplificação de DNA mas também o mais sensível protocolo de detecção de DNA de $T$. gondii.

\section{6 - Patogenia - experimental}

Guimarães et al. 1997(52), compararam um grupo imunossuprimido com um grupo controle, inoculado com a cepa RH. A conclusão foi que o grupo imunossuprimido teve uma evolução pior, antecipando a doença em 24 horas.

Garweg et al. 1998 ${ }^{(53)}$, investigaram o curso da toxoplasmose ocular em modelo animal, infectando 27 coelhos soronegativos com 5000 taquizoítos injetados no tecido subcutâneo e tratando posteriormente com clindamicina por 20 dias, conseguiram salvar 23 coelhos, que foram novamente infectados. Após receberem inoculação peri-retinal com 5000 taquizoítos de toxoplasma, 21 dos 23 coelhos desenvolveram retinocoroidite toxoplásmica, mostrando que o padrão da infecção restri- to a retina mimetiza a situação que acontece em seres humanos, sendo o modelo animal eficiente para o nosso entendimento da patofisiologia da uveíte.

Gormley et al. $1999^{(54)}$, compararam o aparecimento de toxoplasmose ocular e cerebral após inoculação intra-peritoneal e ingestão oral de cistos em hamsters. $\mathrm{O}$ estudo realizado com ingestão oral de cistos conseguiu reproduzir doença ocular e cerebral, confirmada por histologia. O grupo que recebeu os cistos por via oral teve a doença menos severa que os inoculados via intraperitoneal.

Hu et al. 1999(55), desenvolveram um modelo experimental para investigar a patogênese da toxoplasmose ocular adquirida cicatrizada. A conclusão foi que, a inflamação que conseguiram causar em ratos foi dose dependente e o número de 50 parasitas inoculados no olho não conseguia desenvolver inflamação. Quando o número era aumentado para 500 ou 5000 parasitas, alterações inflamatórias ocorriam após 6 dias. A inoculação de 50000 taquizoítos induzia a destruição ocular, levando os ratos a morte após uma semana. Os ratos que haviam sido previamente infectados com $T$. gondii oralmente e depois receberam 50 ou 500 parasitas intra-ocular não desenvolveram inflamação ocular mas os olhos que receberam 5000 parasitas demonstraram retinocoroidite focal necrosante após o oitavo dia da inoculação.

\section{7 - Diagnóstico diferencial - Formas atípicas da toxoplasmose}

Johnson et al. 1997(56), estudaram 7 pacientes imunocompetentes, na faixa etária entre 69 e 82 anos, com a média de 74 anos. Apesar do tratamento com drogas antiparasitárias ter sido instituído no início da doença, o tratamento teve que ser mais longo do que o normal e 4 pacientes tiveram a reativação da retinite, após a suspensão da droga. Houve uma baixa visual na maioria dos casos. Concluíram que a toxoplasmose em pacientes idosos é mais severa devido a baixa da imunidade celular destes pacientes.

Parrat et al. $1999^{(57)}$, relataram um caso de Fuchs' associado a retinocoroidite toxoplásmica e Coeficiente de Desmonts' positivo. Consideraram altamente provável que a etiologia da Síndrome de Fuchs' neste caso tenha sido a toxoplasmose, devido ao alto nível de anticorpos antitoxoplasma encontrados no humor aquoso.

Moraes $1999^{(58)}$, demonstrou que a toxoplasmose pode se localizar nas camadas externas da retina em pacientes com AIDS e não somente em pacientes imunocompetentes como havia sido demonstrado anteriormente.

\section{8 - Complicações - Descolamento da retina}

Bosch-Driessen et al. 2000 ${ }^{(59)}$, estudaram 150 pacientes com toxoplasmose ocular, que foram examinados entre $1990 \mathrm{e}$ 1997 , e encontraram $6 \%$ de descolamento da retina em pacientes com toxoplasmose ocular. Concluíram que deve ser feito um exame cuidadoso da retina em pacientes com toxoplasmose ocular, especialmente naqueles que tem associado outros fatores de risco como miopia e inflamações intra-oculares muito severas. 


\section{9 - Tratamento}

Melamed et al. $1997^{(60)}$, analisaram o uso de fármacos utilizados no tratamento da toxoplasmose, em gestantes com toxoplasmose ocular ativa, classificando-os segundo o fator de risco fetal. Os autores sugerem um esquema terapêutico para a gestante portadora de toxoplasmose ocular.

Gormley et al. $1998^{(61)}$, estudaram o efeito de atovaquone comparado com a terapia convencional (pirimetamina combinada com sulfadiazina, clindamicina e espiramicina) em hamsters. Nenhuma das drogas administradas alterou o curso da doença aguda, avaliada por critérios clínicos. O atovaquone sozinho reduziu significativamente o número de cistos de toxoplasma após a doença aguda, assim como reduziu o número de cistos em doença crônica. Concluíram que o atovaquone tem o potencial de reduzir o risco de recorrências da doença.

Hacker et al. $1998^{(62)}$, fizeram um estudo retrospectivo de 30 pacientes tratados com sulfadiazina e pirimetamina e 14 pacientes tratados com espiramicina, comparando os resultados. O resultado mostrou que, no grupo que tomou espiramicina, a melhora ocorreu em 63,83 dias em comparação a 88 dias do grupo tratado com sulfadiazina e pirimetamina. Os efeitos colaterais foram menores no grupo tratado com espiramicina. Concluíram que a espiramicina é um tratamento eficiente e deve ser considerado como uma opção para o tratamento da retinocoroidite toxoplásmica.

Rothova et al. $1998^{(63)}$, investigaram a eficácia da azitromicina em pacientes com toxoplasmose ocular. Onze pacientes imunocompetentes com doença ocular foram tratados com azitromicina $500 \mathrm{mg}$ no primeiro dia, seguidos por $250 \mathrm{mg} / \mathrm{dia}$ por 5 semanas. O resultado mostrou que a inflamação intraocular desapareceu em 4 semanas em 7 pacientes, inclusive em 2 casos com retinite progressiva, que haviam sido tratados previamente com sulfadiazina, pirimetamina e ácido folínico. A recorrência da retinite ocorreu em 3 pacientes (27\%), com 1 ano de acompanhamento. Não foram observados efeitos colaterais com a azitromicina. A conclusão foi de que, mesmo que a azitromicina não seja preventiva de recorrência de doença, ela pode ser uma alternativa eficaz para tratar pacientes com toxoplasmose ocular, que não puderam tolerar as terapias "standard".

Melamed $1998^{(64)}$, analisa os tratamentos disponíveis para o tratamento da toxoplasmose ocular, comentando sobre as drogas de uso clássico, as drogas alternativas e outras modalidades de tratamento. Faz considerações sobre o tratamento da toxoplasmose ocular no neonato e lactente; na gravidez e no paciente aidético.

Pearson et al. $1999^{(65)}$, avaliaram o efeito do atovaquone em pacientes imunocompetentes com retinocoroidite toxoplásmica. 17 pacientes imunocompetentes entre 18 e 75 anos, com evidências sorológicas e clínicas de toxoplasmose ocular, foram avaliados. O tratamento foi feito com 750mg de atovaquone, 4 vezes ao dia por 3 meses. Após o terceiro dia de tratamento foi acrescentada a prednisona $40 \mathrm{mg}$, que foi diminuída após a resolução da inflamação. O resultado mostrou que a maioria dos pacientes não apresentou efeitos colaterais.
A acuidade visual estabilizou ou aumentou em todos os pacientes. A média inicial da acuidade visual era 20/200 e a média final foi de 20/25. De uma maneira geral o atovaquone foi bem tolerado. Concluíram que o atovaquone é melhor tolerado que as terapias convencionais para toxoplasmose e, aparentemente, é pelo menos tão efetivo quanto as outras no tratamento de toxoplasmose ocular de pacientes imunocompetentes.

Belfort Jr et al. 2000 ${ }^{(66)}$, testaram a eficácia da associação do trimetoprim e sulfametoxazol na prevenção de recidivas em pacientes com retinocoroidite toxoplásmica, em um clinical trial randomizado. Cento e vinte e quatro pacientes foram acompanhados pelo período de 20 meses. Dos 61 pacientes tratados, 4 apresentaram recidiva e dos 63 não tratados, 15 tiveram recidiva. A proteção foi de $74 \%$. O estudo prospectivo demonstrou que a utilização destas drogas é um método eficaz para reduzir as reativações da retinocoroidite toxoplásmica.

\section{AGRADECIMENTO}

Agradecemos à Dra. Luciana Peixoto, que nos auxiliou na pesquisa bibliográfica.

\section{REFERÊNCIAS}

1. Wilder HC. Toxoplasma chorioretinitis in adults. Arch Ophthalmol 1952;48:127-36.

2. Perkins ES. Ocular toxoplasmosis. Br J Ophthalmol 1973;57:1.

3. Akstein RB, Wilson LA, Teutsch SM. Acquired toxoplasmosis. Am Acad Ophthalmol 1982;89:1299-302.

4. Green R. Histopathology of ocular toxoplasmosis. In: Bialasiewicz AA, Schaal KP. Infectious diseases of theeye. Holanda: Aeolus; 1994. p. 454-61.

5. Silveira C, Belfort Jr R, Burnier Jr M. Toxoplasmose ocular. Identificação de cistos de Toxoplasma gondii na retina de irmãos não gêmeos com diagnóstico de toxoplasmose ocular recidivante: primeiro caso mundial. Arq Bras Oftalmol 1987;50:215-8.

6. Glasner PD, Silveira C, Kruszon-Moran D, Martins MC, Burnier Jr M, Silveira $\mathrm{S}$ et al. An unusually high prevalence of ocular toxoplasmosis in Southern Brazil. Am J Ophthalmol 1992;14:136-44.

7. Belfort Jr R, Silveira C, Muccioli C, Abreu MT, Martins MC, Victora C. Incidence of acquired ocular toxoplasmosis seroconversion and clinical course in a prospective study (7 year follow up). [abstract 2019 ] Invest Ophthalmol and Vis Sci 1999;40(4 Suppl):383.

8. Altintas N, Kuman HA, Akisu C, Aksoy U, Atambay M. Toxoplasmosis in last four years in Agean region, Turkey. J Egipt Soc Parasitol 1997;27:439-43.

9. Joshi YR, Vyas S, Joshi KR. Seroprevalence of toxoplasmosis in Jodhpur, India. J Commun Dis 1998;30:32-7.

10. Jain SD, Uppal B, Mehta DK. Seroepidemiology of ocular toxoplasmosisprofile of an urban population. Indian J Pathol Microbiol 1998;41:387-90.

11. Abreu MT, Boni D, Belfort Jr R, Passos A, Garcia AR, Muccioli C et al. Toxoplasmose ocular em Venda Nova do Imigrante, ES, Brasil. Arq Bras Oftalmol 1998;61:540-5.

12. Garcia JL, Navarro IT, Ogawa L, Oliveira RC, de Kobilka E. Seroprevalence, epidemiology and ocular evaluation of human toxoplasmosis in the rural zone Jaguapita (Parana) Brazil. Rev Panam Salud Publica 1999;6:157-63.

13. Gilbert RE, Dunn DT, Lightman S, Murray PI, Pavesio CE, Gormley PD et al. Incidence of symptomatic toxoplasma eye disease: aetiology and public health implications. Epidemiol Infect 1999;123:283-9.

14. Oréfice F. Prevalência da toxoplasmose ocular em Campos dos Goitacazes, RJ. Estudo Interinstitucional 1999. In: Oréfice F. Uveíte clínica e cirúrgica. Rio de Janeiro: Cultura Médica; 2000. v. 2

15. Kamiyama M, Yamamoto S, Hayasaka S. Right active retinitis and left focal retinochoroidal scar in a girl with congenital toxoplasmosis. Ophthalmologica 1997;211:95-7. 
16. Mets MB, Holfels E, Boyer KM, Swisher CN, Roizen N, Stein L, et al. Eye manifestations of congenital toxoplasmosis. Am J Ophthalmol 1997;123:1-16.

17. Melamed J, Kruter DW, Dornelles F. Alterações cerebrais e oculares na toxoplasmose congênita: estudo preliminar. [resumo 50]. Arq Bras Oftalmol 1998;61:418.

18. Ianaguihara EM, Spera CA, Moraes NSB, Guia T. Toxoplasmose ocular congênita bilateral em gêmeas univitelinas.[resumo 32]. Arq Bras Oftalmol 1998;61:410.

20. Malm G, Tear Fahnehjelm K, Wiklund S, Engman ML, Ivarsson SA, Petersson K, et al. Three children with congenital toxoplasmosis: early report from a Swedish prospective screening study. [commented on Acta Paediatr 1999; 88:586-8] Acta Paediatr 1999;88:667-70.

19. O'Neil JF. The ocular manifestations of congenital infection: a study of the early effect and long-term outcome of maternally transmitted rubella and toxoplasmosis. Trans Am Ophthalmol Soc 1998;96:813-79.

21. Burnett AJ, Shortt SG, Isaac-Renton J, King A, Werker D, Bowie WR Multiple cases of acquired toxoplasmosis retinitis presenting in an outbreak. Ophthalmology 1998;105:1032-7.

22. Pereira M de F, Silva DA, Ferro EA, Mineo JR. Acquired and congenital ocular toxoplasmosis experimentally induced in Calomys callosus (Rodentia, Cricetidae). Mem Inst Oswaldo Cruz 1999;94:103-14.

23. Gilbert RE, Stanford MR. Is ocular toxoplasmosis caused by prenatal or postnatal infection? Br J Ophthalmol 1999;84:224-6.

24. Holland GN, Muccioli C, Silveira C, Weisz JM, Belfort Jr. R, O’Connor R. Intraocular inflammatory reactions without focal necrotizing retinochoroiditis in patients with acquired systemic toxoplasmosis. Am J Ophthalmol 1999; 128:413-20.

25. Yamamoto JH, Vallochi AL, Silveira C, Kalil Filho J, Nussenblatt RB, Cunha-Neto E, et al. Discrimination between patients with acquired toxoplasmosis and congenital toxoplasmosis on the basis of the immune response to parasite antigens. J Infect Dis 2000;181:2018-22.

26. Joag SV, Li Z, Foresman L, Pinson DM, Raghavan R, Zhuge W, et al. Characterization of the pathogenic KU-SHIV model of acquired immunodeficiency syndrome in macaques. AIDS Res Hum Retroviruses 1997;13: 635-45.

27. Arevalo JF, Quiceno JI, Garcia RF, McCutchan JA, Munguia D, Nelson JA, et al. Retinal findings and characteristics in AIDS patients with sistemic Micobacterium avium-intracellulare complex and toxoplasmic encephalitis. Ophthalmics Surg Lasers 1997;28:50-4.

28. Girard B, Prevost-Moravia G, Courpotin C, Lasfargues G. Ophthalmologic manifestations observed in a pediatric HIV-seropositive population. J Fr Ophthalmol 1997;20:49-60.

29. Lanjewar DN, Surve KV, Maheshwari MB, Shenoy BP, Hira SK Toxoplasmosis in the central nervous system in the acquired immunodeficiency syndrome. Indian J Pathol Microbiol 1998;41:147-51.

30. Chakraborty J. HIV/AIDS and ocular manifestations. J Indian Med Assoc 1999;97:299-304.

31. McHugh TD, Bathgate T, Mangan J, Johnson JD, Holliman RE, Butcher PD. Recognition of tissue cyst-specific antigens in reactivating toxoplasmosis. J Med Microbiol 1997;46:587-95.

32. Whittle RM, Wallace GR, Whiston RA, Dumonde DC, Stanford MR Human antiretinal antibodies in toxoplasma retinochoroiditis. $\mathrm{Br} \mathrm{J}$ Ophthalmol 1998;82:1017-21.

33. Gomez Marin JE, Pinon JM, Bonhomme A, Guenounou M. Does human toxoplasmosis involve an imbalance in T1/T2 cytokines? Med Hypotheses 1997;48:161-9

34. Lappin MR, Dow SW, Reif JS, Chavkin MJ. Elevated interleukin 6 activity in aqueous humor of cats with uveitis. Vet Immunol Immunopathol 1997;58:17-26

35. Danise A, Cinque P, Vergani S, Candino M, Racca S, De Bona A, Novati R, Castagna A. Use of polymerase chain reaction assays of aqueous humor in the differential diagnosis of retinitis in patients infected with human immunodeficiency virus. Clin Infect Dis 1997;24:1100-6.

36. Bornand JE, de Gottrau P. Uveitis: is ocular toxoplasmosis only a clinical diagnosis? Ophthalmologica 1997:211:87-9.

37. Quentin CD, Reiber H. Analysis of aqueous humor in intraocular toxoplasmosis]. [commented on Ophthalmologe 1998;95:120-1]. Ophthalmologe 1997;94:728-31.

38. Bernasconi O, Auer C, Herbort CP. Recurrent toxoplasmic retinochoroiditis Significance of perilesional satellite dark dots seen by indocyanine green angiography. Ocul Immunol Inflamm 1997;5:207-11.

39. Garweg JG, Jacquier P, Fluckiger F. Current limits in a diagnosis of ocular toxoplasmosis. Klin Monatsbl Augenheilkd 1998;212:330-3.
40. Ongkosuwito JV, Feron EJ, van Doornik CE, Van der Lelij A, Hoyng CB, La Heij EC, et al. Analysis of immunoregulatory cytokines in ocular fluid samples from patients with uveitis. Invest Ophthalmol Vis Sci 1998;39:2659-65.

41. Burney DP, Chavkin MJ, Dow SW, Potter TA, Lappin MR. Polymerase chain reaction for the detection of Toxoplasma gondii within aqueous humor of experimentally-inoculated cats. Vet Parasitol 1998;79:181-6.

42. Klaren VN, Van Doornik CE, Ongkosuwito JV, Feron EJ, Kijlstra A. Differences between intraocular and serum antibody responses in patients with ocular toxoplasmosis. Am J Ophthalmol 1998;126:698-706.

43. Ronday MJ, Ongkosuwito JV, Rothova A, Kijlstra A. Intraocular antiToxoplasma gondii IgA antibody production in patients with ocular toxoplasmosis. Am J Ophthalmol 1999;127:294-300.

44. Paul M. Immunoglobulin $\mathrm{G}$ avidity in diagnosis of toxoplasmic lymphadenopathy and ocular toxoplasmosis. Clin Diagn Lab Immunol 1999;6:514-8.

45. Chapman DJ, Ashburn D, Ogston SA, Ho-Yen DO. The relationship between ocular toxoplasmosis and levels of specific toxoplasma antibodies. Epidemiol Infect 1999;122:299-303.

46. Montoya JG, Parmley S, Liesenfeld O, Jaffe GJ, Remington JS. Use of the polymerase chain reaction for diagnosis of ocular toxoplasmosis. Ophthalmology 1999;106:1554-63.

47. Bou G, Figueroa MS, Marti-Belda P, Navas E, Guerrero A. Value of PCR for detection of Toxoplasma gondii in aqueous humor and blood samples from immunocompetent patients with ocular toxoplasmosis. J Clin Microbiol 1999;37:3465-8.

48. Roberts F, Roberts CW, Ferguson DJ, McLeod R. Inhibition of nitric oxide production exacerbates chronic ocular toxoplasmosis. Parasite Immunol 2000;22:1-5.

49. Nagineni CN, Detrick B, Hooks JJ. Toxoplasma gondii infection induces gene expression and secretion of interleukin 1(IL-1), IL-6, granulocytemacrophage colony-stimulating factor, and intercellular adhesion molecule 1 by human retinal pigment epithelial cells. Infect Immun 2000;68:407-10.

50. Garweg JG, Jacquier P, Boehnke M. Early aqueous humor analysis in patients with human ocular toxoplasmosis. J Clin Microbiol 2000;38:996-1001.

51. Jones CD, Okhravi N, Adamson P, Tasker S, Lightman S. Comparison of PCR Detection Methods for B1, P30, and 18S rDNA Genes of T. gondii in Aqueous Humor. Invest Ophthalmol Vis Sci 2000;41:634-44.

52. Guimaraes AC, Kawarabayashi M, Nunes EV, Ferraz SN, Chiosini CB, Tolezano JE, et al. Experimental toxoplasmosis, and immunosuppression. Rev Hosp Clin Fac Med São Paulo 1997;52:316-20.

53. Garweg JG, Kuenzli H, Boehnke M. Experimental ocular toxoplasmosis in naive and primed rabbits. Ophthalmologica 1998;212:136-41.

54. Gormley PD, Pavesio CE, Luthert P, Lightman S. Retinochoroiditis is induced by oral administration of Toxoplasma gondii cysts in the hamster model. Exp Eye Res 1999;68:657-61.

55. Hu MS, Schwartzman JD, Lepage AC, Khan IA, Kasper LH. Experimental ocular toxoplasmosis induced in naive and preinfected mice by intracameral inoculation. Ocul Immunol Inflamm 1999;7:17-26.

56. Johnson MW, Greven GM, Jaffe GJ, Sudhalkar H, Vine AK. Atypical, severe toxoplasmic retinochoroiditis in elderly patients. Ophthalmology 1997;104:48-57.

57. Parrat E, Brousse D, Cousin P, L'Herron F, Touameur S, Charpentier D, et al. Fuch's uveitic syndrome in a patient with ocular toxoplasmosis. J Fr Ophthalmol 1999;22:1067-71.

58. Moraes Jr HV. Punctate outer retinal toxoplasmosis in an HIV-positive child. Ocul Immunol Inflamm 1999;7:93-5.

59. Bosch-Driessen LH, Karimi S, Stilma JS, Rothova A. Retinal detachment in ocular toxoplasmosis. Ophthalmology 2000;107:36-40.

60. Melamed J, Gus P, Alvarenga Z. Tratamento da toxoplasmose ocular na gestação. Rev Bras Oftalmol 1997;56:241-8.

61. Gormley PD, Pavesio CE, Minnasian D, Lightman S. Effects of drug therapy on Toxoplasma cysts in an animal model of acute and chronic disease. Invest Ophthalmol Vis Sci 1998;39:1171-5.

62. Hacker M, Richter R, Gumbel H, Richter T, Ohrloff C. Toxoplasmosis retinochoroiditis, a therapy comparison between spiramycin and pyrimethamine/sulfadiazine]. Klin Monatsbl Augenheilkd 1998;212:84-7.

63. Rothova A, Bosch-Driessen LE, Van Loon NH, Treffers WF. Azithromicin for ocular toxoplasmosis. Br J Ophthalmol 1998;82:1306-8.

64. Melamed J. Tratamento da toxoplasmose ocular. Rev Bras Oftalmol 1998; 57:159-63.

65. Pearson PA, Piracha AR, Sen HA, Jaffe GJ. Atovaquone for the treatment of toxoplasma retinochoroiditis in immunocompetent patients. Ophthalmology 1999;106:148-53.

66. Belfort Jr R, Silveira C, Muccioli C, Horta BL, Victora C. Trimetoprim and sulfametoxazol for the prevention of toxoplasmic retinochoroiditis recurrences.[abstract 501]. Invest Ophthalmol Vis Sci 2000;41(Suppl 4 ):S95. 